\title{
Characterization of Tuberculosis Cases Presenting in a Tertiary Healthcare Facility in South-Eastern Nigeria
}

\author{
E. D. Adinma1, E. C. Azuike1 ${ }^{*}$, S. A. Nwabueze1, C. C. Nnebue', E. D. Azuike², D. C. Obi1, \\ I. C. Iloghalu' ${ }^{1}$ K. N. Okonkwo' ${ }^{1}$ M. C. Ohamaeme ${ }^{1}$ \\ ${ }^{1}$ Department of Community Medicine, Nnamdi Azikiwe University Teaching Hospital, Nnewi, \\ Nigeria \\ ${ }^{2}$ Department of Nursing Science, College of Health Sciences, Nnamdi Azikiwe University, Awka, \\ Nigeria \\ Email: ${ }^{*}$ emmanazuike@yahoo.com
}

Received 27 July 2014; revised 29 August 2014; accepted 21 September 2014

Copyright (C) 2014 by authors and Scientific Research Publishing Inc.

This work is licensed under the Creative Commons Attribution International License (CC BY). http://creativecommons.org/licenses/by/4.0/

(c) (i) Open Access

\begin{abstract}
Background: Tuberculosis is second only to HIV/AIDS as the greatest killer worldwide, due to a single infectious agent. Directly Observed Treatment Short-Course (DOTS) is presently the WHO recommended programme to fight tuberculosis worldwide. There is need to understand the characteristics of patients who receive treatment for tuberculosis. This will help modify the strategies to fight the scourge of tuberculosis. Methods: This was a retrospective study conducted at the DOTS clinic at Nnamdi Azikiwe University Teaching Hospital Nnewi, Anambra State, Nigeria. The records of patients who received treatment from the clinic from $1^{\text {st }}$ January 2012 to $31^{\text {st }}$ December 2012 were reviewed. Three hundred and fifteen patients were included in the study. Important characteristics of the patients were retrieved. Associations between patients' characteristics were determined using relevant tests of significance. Results: Three hundred and fifteen patients were included in the study. There were more male patients (59\%). The reproductive age group (37.5\%) was more than the other age groups. Mean age was $33.1( \pm 18.5)$ years. There were more rural patients $(50.2 \%)$ than urban patients $(49.8 \%)$. There were more pulmonary TB patients $(87.3 \%)$ than extrapulmonary TB patients $(12.7 \%)$. There were more sputum AFB negative patients (45.4\%) than positive patients $(41.3 \%)$. There were more HIV negative patients $(59.4 \%)$ than positive patients (40.6\%). Conclusion: This study demonstrated some important characteristics of tuberculosis patients. Such knowledge if taken into consideration in the tuberculosis control programme will definitely improve the outcome of the programme.
\end{abstract}

\footnotetext{
"Corresponding author.
}

How to cite this paper: Adinma, E.D., et al. (2014) Characterization of Tuberculosis Cases Presenting in a Tertiary Healthcare Facility in South-Eastern Nigeria. Open Journal of Preventive Medicine, 4, 723-729. 


\section{Keywords}

\section{Characteristics, Tuberculosis Patients, DOTS, Nigeria}

\section{Introduction}

Tuberculosis (TB) is a disease arising from infection by Mycobacterium tuberculosis [1]. Tuberculosis can affect almost any organ of the body but the lung is the most susceptible organ, making pulmonary tuberculosis the commonest type of tuberculosis. Tuberculosis occurs worldwide [2]. Tuberculosis is a major public health problem globally. Tuberculosis is second only to HIV/AIDS as the greatest killer worldwide, due to a single infectious agent [3]. In 2012, 8.6 million people fell ill with TB and 1.3 million died from TB [3]. Over 95\% of TB deaths occur in low and middle income countries and it is among the top three causes of death for women aged 15 to 44 years [3]. In 2012 an estimated 530,000 children became ill with TB and 74,000 HIV negative children died of TB [3]. People infected with TB have a lifetime risk of falling ill with TB of $10 \%$, however persons with compromised immune systems, such as people living with HIV, malnutrition or diabetes, or people who use tobacco, have a much higher risk of falling ill [3]. Sub-Saharan Africa had the greatest proportion of new cases of TB per population, with over 255 cases per 100,000 population in the year 2012 [3]. According to the United States Agency for International Development (USAID), Nigeria ranks fourth among the 22 high-burden TB countries in the world [4]. Nigeria established its National TB and Leprosy Control Programme (NTBLCP) in 1989. The NTBLCP operates along the three levels of government: National, State and Local Government Areas, with coordinating offices at each level. Nigeria adopted the Directly Observed Treatment Short course (DOTS) strategy in 1994. Health facilities at the peripheral level are the operational units of DOTS services. As of 2009, there were 3455 health facilities providing free TB and DOTS services in Nigeria [4]. TB is a social disease with medical aspects. The social factors include many non-medical factors such as poor quality of life, poor housing, overcrowding, under-nutrition, lack of education, large families and lack of awareness of causes of illness [5]. TB is more prevalent in males than in females. Also in developing countries, there is a sharp rise in infection rates from infancy to adolescence. However in developed countries, the disease is more common in the elderly [5]. Drug regimens for treatment of TB are grouped into category one and category two. Category one is used for brand new cases who have not been treated for TB ever in their lives. Category two regimen is for failures after category one treatment, and for relapse cases who came down with TB again after they have been treated with category one and they recovered.

The aim of this study is to describe the characteristics of patients that received treatment for TB at Nnamdi Azikiwe University Teaching Hospital (NAUTH) Nnewi DOTS clinic for the period $1^{\text {st }}$ January 2012 to $31^{\text {st }}$ December 2012.

\section{Methodology}

This is a retrospective study conducted at the DOTS clinic of NAUTH Nnewi. The clinic register was the source of data. The inclusion criteria were all patients who received treatment for TB for the period $1^{\text {st }}$ January 2012 to $31^{\text {st }}$ December 2012. Patients who received treatment before or after this duration were excluded. Specific characteristics of these patients were extracted using a structured proforma. Characteristics sought included age, sex, place of residence, initial sputum AFB test result, site of TB infection, Treatment regimen, category of patient and HIV status. The collected data was entered into International Business Machines-Statistical Package for Social Sciences (IBM-SPSS) version 20, and analyzed. Chi square test was used to test for association between variables.

\section{Results}

Three hundred and fifteen patients were treated for tuberculosis in the DOTS clinic during the period under review. The 315 patients' data were available via the clinic register.

Table 1 shows the characteristics of the patients. There were more males (59\%) than females (41\%). The commonest age group was the group 20 - 39 years (37.5\%). The mean age was $33.1( \pm 18.5)$. There were more 
Table 1. Socio-demographic characteristics of the patients.

\begin{tabular}{cc}
\hline Variable & Frequency (\%) $\mathbf{N}=\mathbf{3 1 5}$ \\
Sex & $186(59)$ \\
Male & $129(41)$ \\
Female & \\
Age (in years) & $74(23.5)$ \\
$<20$ & $118(37.5)$ \\
$20-39$ & $104(33.0)$ \\
$40-59$ & $19(6.0)$ \\
$\geq 60$ & \\
Residence & $157(49.8)$ \\
Urban & $158(50.2)$ \\
Rural &
\end{tabular}

rural patients (50.2\%) than urban patients (49.8\%).

Table 2 shows that the patients on category 1 regimen (83.5\%) were more than those on category 2 regimen (16.5\%). Most patients had pulmonary TB (87.3\%) as against extrapulmonary TB (12.7\%). More patients had negative sputum AFB results (45.3) than positive results (41.3\%), while $13.3 \%$ could not produce sputum. There were more HIV negative patients (59.4\%) than HIV positive patients (40.6\%).

Table 3 shows that there was a statistically significant association between the age and HIV status of the patients $\left(X^{2}=9.229, p=0.03\right.$, with the age groups $20-39$ and $40-59$ having the highest proportion of HIV positive patients (38.3\% and $38.3 \%$ respectively). Also the proportion of the rural patients who were HIV positive (57.0\%) was higher than the urban patients who were HIV positive $(43.0 \%)\left(X^{2}=4.074, p=0.04\right)$. Also more HIV positive patients had pulmonary TB (95.3\%) than extrapulmonary (4.7\%) and this was statistically significant $\left(\mathrm{X}^{2}=12.482, \mathrm{p}=0.00\right)$.

Table 4 shows that a higher proportion of the patients with positive sputum AFB results received category 1 regimen $(89.2 \%)$ as against category 2 patients $(26.9 \%)$ and this was statistically significant $\left(\mathrm{X}^{2}=8.229, \mathrm{p}=\right.$ 0.02). As expected there was statistically significant association between the type of TB and the sputum AFB result as none of the patients that had extrapulmonary TB had positive sputum AFB result, while all the patients that were sputum AFB positive had pulmonary TB $(100 \%),\left(X^{2}=36.464, p=0.00\right)$. Also there was statistically significant association between age and sputum AFB status $\left(X^{2}=125.116, p=0.00\right)$.

Table 5 shows that there was a statistically significant association between the AFB status of the clients and the site of their disease. Also the HIV status and place of residence of the clients has a statistically significant association with the site of disease.

\section{Discussion}

In this study there were more male than female TB patients and this agrees with the findings of many other studies [6]-[9]. The commonest age group was the group 20 - 39 years. This is similar to the findings of other studies [9] [10] and agrees with the generally accepted knowledge that TB affects the reproductive age groups [3]. In this study there were more rural patients than urban patients. This agrees with the findings of a study done in India [11] but contrasts with the finding of another study done in India where the urban patients were more [12]. More patients had pulmonary TB (87.3\%) than extrapulmonary TB (12.7\%). Similar findings were reported in other studies [13]-[15] and agreed with generally accepted prevalence of extrapulmonary TB among all cases of TB [16]. More clients in this study had sputum AFB negative results (45.3\%) than sputum positive results (41.3\%). Several studies have reported such findings [6] [8].

There were more HIV negative patients than HIV positive patients in this study. This HIV/TB coinfection rate was much higher than that reported in a South African study (18\%) [17]. This may be because this centre is a referral centre for both TB and HIV treatment. But a higher coinfection rate was reported in a hospital in Johannesburg, South Africa (95\%) [18], this very high coinfection rate, which the authors reported as the highest ever reported in the peer-reviewed English literature may reflect the selection bias for in-patients in their study, who generally would have more co-existing conditions than outpatients do. It is also worthy of note that a much 
Table 2. Distribution of patients by disease site, AFB status, HIV status and regimen.

\begin{tabular}{cc}
\hline Variable & Frequency (\%) N = 315 \\
Disease site & $275(87.3)$ \\
Pulmonary & $40(12.7)$ \\
Extra pulmonary & \\
Sputum AFB status & $130(41.3)$ \\
Positive & $143(45.4)$ \\
Negative & $42(13.3)$ \\
Couldn’t produce sputum & \\
HIV status & $128(40.6)$ \\
Positive & $187(59.4)$ \\
Negative & \\
Regimen & $263(83.5)$ \\
Category 1 & $52(16.5)$ \\
Category 2
\end{tabular}

Table 3. Association between HIV status of patients and some characteristics.

\begin{tabular}{|c|c|c|c|c|c|}
\hline Variables & HIV positive & HIV negative & Total & $\mathrm{X}^{2}$ & P value \\
\hline & $N=128$ & $N=187$ & $N=315$ & & \\
\hline & n (\%) & n (\%) & n (\%) & & \\
\hline \multicolumn{6}{|l|}{ Sex } \\
\hline Male & $64(50)$ & $122(65.2)$ & $186(59.0)$ & 7.299 & $0.01^{*}$ \\
\hline Female & $64(50)$ & $65(34.8)$ & $129(41.0)$ & & \\
\hline \multicolumn{6}{|l|}{ Age (years) } \\
\hline$<20$ & 28 (21.9) & $46(24.6)$ & $74(23.5)$ & 9.229 & $0.03^{*}$ \\
\hline $20-39$ & 49 (38.3) & 69 (36.9) & $118(37.5)$ & & \\
\hline $40-59$ & 49 (38.3) & $55(29.4)$ & $104(33.0)$ & & \\
\hline$\geq 60$ & $2(1.6)$ & $17(9.1)$ & $19(6.0)$ & & \\
\hline \multicolumn{6}{|l|}{ Residence } \\
\hline Urban & $55(43.0)$ & $102(54.5)$ & $157(49.8)$ & 4.074 & $0.04^{*}$ \\
\hline Rural & $73(57.0)$ & 85 (45.5) & $158(50.2)$ & & \\
\hline \multicolumn{6}{|l|}{ Regimen } \\
\hline Category 1 & $108(84.4)$ & 155 (82.9) & $263(83.5)$ & 0.122 & 0.73 \\
\hline Category 2 & $20(15.6)$ & $32(17.1)$ & $52(16.5)$ & & \\
\hline \multicolumn{6}{|l|}{ Site of disease } \\
\hline Pulmonary & $122(95.3)$ & $153(81.8)$ & $275(87.3)$ & 12.482 & $0.00^{*}$ \\
\hline Extrapulmonary & $6(4.7)$ & $34(18.2)$ & 40 (12.7) & & \\
\hline \multicolumn{6}{|l|}{ Sputum AFB status } \\
\hline Positive & $45(35.2)$ & 85 (45.5) & $130(41.3)$ & 5.211 & 0.07 \\
\hline Negative & $68(53.1)$ & $75(40.1)$ & $143(45.4)$ & & \\
\hline Couldn’t produce sputum & $15(11.7)$ & $27(14.4)$ & 42 (13.3) & & \\
\hline
\end{tabular}

*Statistically significant.

lesser HIV/TB coinfection rate (9.4\%) was reported in New Delhi, India [19].

HIV is generally known to be more in the reproductive age [20] [21]. This was corroborated in this study as the age groups with the highest frequencies of HIV positive status among the respondents were of the reproductive stage and this was statistically significant. This is understandable because the commonest mode of transmission of HIV remains the sexual route [21] [22], and these age groups are the most sexually active age groups. Among the HIV positive TB patients more reside in the rural area and this was statistically significant. This is 
Table 4. Association between sputum AFB status and some characteristics.

\begin{tabular}{|c|c|c|c|c|c|c|}
\hline Variables & Positive & Negative & Couldn’t produce sputum & Total & $X^{2}$ & P value \\
\hline & $N=130$ & $N=143$ & $N=42$ & $\mathbf{N}=315$ & & \\
\hline & n (\%) & n (\%) & n (\%) & n (\%) & & \\
\hline \multicolumn{7}{|l|}{ Sex } \\
\hline Male & $76(58.5)$ & $87(60.8)$ & $23(54.8)$ & $186(59.0)$ & 0.527 & 0.77 \\
\hline Female & $54(41.5)$ & $56(39.2)$ & $19(45.2)$ & $129(59.0)$ & & \\
\hline \multicolumn{7}{|l|}{ Residence } \\
\hline Urban & $63(48.5)$ & $72(50.3)$ & $22(52.4)$ & $157(49.8)$ & 0.222 & 0.90 \\
\hline Rural & $67(51.5)$ & $71(49.7)$ & $20(47.6)$ & $158(50.2)$ & & \\
\hline \multicolumn{7}{|l|}{ Regimen } \\
\hline Category 1 & 116 (89.2) & 110 (76.9) & $29(69.0)$ & 275 (87.3) & 36.464 & $0.00^{*}$ \\
\hline Category 2 & $14(26.9)$ & $33(23.1)$ & $5(11.9)$ & $53(16.5)$ & & \\
\hline \multicolumn{7}{|l|}{ Site of disease } \\
\hline Pulmonary & $130(100)$ & $116(81.1)$ & $29(69.0)$ & 275 (87.3) & 36.464 & $0.00^{*}$ \\
\hline Extrapulmonary & $0(0.0)$ & 27 (18.9) & $13(31.0)$ & 40 (12.7) & & \\
\hline \multicolumn{7}{|l|}{ HIV status } \\
\hline Positive & $45(34.6)$ & $68(47.6)$ & 15 (35.7) & $128(40.6)$ & 5.211 & 0.07 \\
\hline Negative & $85(65.4)$ & $75(52.4)$ & 27 (64.3) & $187(59.4)$ & & \\
\hline \multicolumn{7}{|l|}{ Age (years) } \\
\hline$<20$ & $11(8.5)$ & 25 (17.5) & 38 (90.5) & 74 (23.5) & 125.116 & $0.00^{*}$ \\
\hline $20-39$ & 61 (46.9) & 57 (39.9) & $0(0.0)$ & $118(37.5)$ & & \\
\hline $40-59$ & $50(38.5)$ & 51 (35.7) & $3(7.1)$ & $104(33.0)$ & & \\
\hline$\geq 60$ & $8(6.2)$ & $10(7.0)$ & $1(2.4)$ & $19(6.0)$ & & \\
\hline
\end{tabular}

*Statistically significant.

Table 5. Association between site of diseases and some characteristics.

\begin{tabular}{|c|c|c|c|c|c|}
\hline Variables & Pulmonary & Extrapulmonary & Total & $X^{2}$ & $P$ value \\
\hline & $N=275$ & $N=40$ & $\mathbf{N}=315$ & & \\
\hline & n (\%) & n (\%) & n (\%) & & \\
\hline \multicolumn{6}{|l|}{ Sex } \\
\hline Male & $161(58.5)$ & $25(62.5)$ & $186(59.0)$ & 0.226 & 0.64 \\
\hline Female & $114(41.5)$ & $15(37.5)$ & $129(41.0)$ & & \\
\hline \multicolumn{6}{|l|}{ Sputum AFB status } \\
\hline Positive & $130(47.3)$ & $0(0.0)$ & $130(41.3)$ & 36.46 & $0.00^{*}$ \\
\hline Negative & $116(42.2)$ & $27(67.5)$ & $143(45.4)$ & & \\
\hline Couldn’t produce sputum & $29(10.5)$ & $13(32.5)$ & $42(13.3)$ & & \\
\hline \multicolumn{6}{|l|}{ HIV status } \\
\hline Positive & $122(44.4)$ & $6(15.0)$ & $128(40.6)$ & 12.482 & $0.00^{*}$ \\
\hline Negative & $153(55.6)$ & $34(85.0)$ & $187(59.4)$ & & \\
\hline \multicolumn{6}{|l|}{ Age (years) } \\
\hline$<20$ & $58(78.4)$ & $16(21.6)$ & $74(23.5)$ & 7.584 & 0.06 \\
\hline $20-39.9$ & $107(90.7)$ & $11(0.0)$ & 118 (37.5) & & \\
\hline $40-59.9$ & $94(90.4)$ & $10(9.6)$ & $104(33.0)$ & & \\
\hline$\geq 60$ & $16(84.2)$ & $3(15.8)$ & $19(6.0)$ & & \\
\hline \multicolumn{6}{|l|}{ Residence } \\
\hline Urban & 129 (46.9) & $28(70.0)$ & 157 (49.8) & 7.448 & $0.01^{*}$ \\
\hline Rural & $146(53.1)$ & $12(30.0)$ & $158(50.2)$ & & \\
\hline \multicolumn{6}{|l|}{ Regimen } \\
\hline Category 1 & 233 (84.7) & $30(75.0)$ & 263 (83.5) & 2.397 & 0.12 \\
\hline Category 2 & 42 (15.3) & $10(25.0)$ & $52(16.5)$ & & \\
\hline
\end{tabular}

*Statistically significant. 
surprising because the prevalence of HIV in Nigeria is higher in the urban areas than in the rural areas [23] [24]. This could be because the centre is a referral centre which serves a lot of surrounding rural local government areas, though located in an urban local government area.

\section{Conclusions and Recommendations}

In this study, there were more male TB patients. The reproductive age group was more affected. There were more pulmonary TB patients than extra-pulmonary TB patients. There were more sputum AFB negative patients. There were more HIV negative patients than HIV positive patients. The HIV/TB coinfection rate was higher in the reproductive age group.

We therefore recommend as follows: there should be more rigorous cases found among males. More efforts to combat TB should be channelled towards the reproductive age group. Health workers should not be in a hurry to conclude that sputum smear negative patients do not have TB, also clinical diagnosis should be intensified. Health workers should be wary of the presence of TB in HIV negative individuals despite the fact that HIV increases susceptibility to TB, and there are more HIV negative TB patients than HIV positive TB patients, besides the window period of HIV detection must be borne in mind. Efforts should be made to prevent HIV among youths. Adolescent friendly clinics should be established. Efforts to combat HIV should not be localized in the urban areas alone, as this study has shown that the rural areas must be given due attention in the fight against HIV.

\section{References}

[1] Haslett, C., Chilvers, E.R., Hunter, J.A. and Boon, N.A. (1999) Davidson’s Principles and Practice of Medicine. 18th Edition, Churchill Livingston, New York.

[2] Lucas, A.O. and Gilles, H.M. (2003) Short Textbook of Public Health Medicine for the Tropics. 4th Edition. Arnord Publishers, London, 159.

[3] World Health Organisation (2014) Tuberculosis Fact Sheet. www.who.int/mediacentre/factsheets/fs104/en/

[4] United States Agency for International Development (USAID) (2014) TB Care Project, Country Details, Nigeria. www.tbcare1.org/countries/africa/nia/

[5] Park, K. (2005) Preventive and Social Medicine. 18th Edition. M/S Banarsidas Bhanot, Jabalpur, 890.

[6] Ogboi, S.J., Idris, S.H., Olayinka, A.T. and Ilyas, J. (2010) Socio-Demographic Characteristics of Patients Presenting with Pulmonary Tuberculosis in A Primary Health Centre, Zaria, Nigeria. Journal of Medical Laboratory and Diagnosis, 1, 11-14.

[7] Ekwueme, O.C., Ezeoke, U.E. and Mgbeokwere, U. (2009) The Prevalence and Socio-Demographic Characteristics of Persons with TB and TB/HIV Co-Infection at the Chest Clinic of the University of Nigeria Teaching Hospital, Enugu, Nigeria. Journal of College of Medicine, 14, 6-17.

[8] Hamid, S., Syed, A.H. and Ali, I. (2012) Sociodemographic Factors Associated with Sputum Positivity Rates for Tuberculosis in Patients with Cough in Srinagar Hospital, India. Pacific Journal of Medical Sciences, 9, 47-52.

[9] Donald, C., Uday, S.S., Sidhyartha, M. and Deepak, S. (2010) Socio-Demographic Profiles of the Delayed Diagnosed Patients in RNTCP, Anand District. Healthline, 1, 45-48.

[10] Lawn, S.D., Bekker, L, Middelkoop, K., Myer L. and Wood R. (2006) Impact of HIVI Infection on the Epidemiology of Tuberculosis in a Peri-Urban Community in South Africa: The Need for Age-Specific Interventions. Clinical Infectious diseases, 42, 1040-1047. http://dx.doi.org/10.1086/501018

[11] Muhammad, U.M., Ubeera, S., Hussain, M.A., Anum, S., Fatima, O., et al. (2011) Urban-Rural Inequities in Knowledge, Attitudes and Practices Regarding Tuberculosis in Two Districts of Pakistan's Punjab Province. International Journal for Equity in Health, 10, 8. http://dx.doi.org/10.1186/1475-9276-10-8

[12] Rajewswani, R., Balasubramanian, R., Muniyadi, M., Geetharamani, S., Theresa, X. and Venkatessa, P. (1999) Socio-Economic Impact of Tuberculosis on Patients and Family in India. The International Journal of Tuberculosis and Lung Disease, 3, 869-877.

[13] Sreeramareddy, C.T., Panduru, K.V., Verma, S.C., Joshi, H.S. and Bates, M.N. (2008) Comparison of Pulmonary and Extrapulmonary Tuberculosis in Nepal-A Hospital-Based Retrospective Study. BMC Infectious Diseases, 8, 8.

[14] Noertjojo, K., Tam, C.M., Chan, S.L. and Chan-Yeung, M.M. (2002) Extra-Pulmonary and Pulmonary Tuberculosis in Hong Kong. The International Journal of Tuberculosis and Lung Disease, 6, 879-886.

[15] Musellin, B., Erturan, S., Sonmez, D.E. and Ongen, G. (2005) Comparison of Extrapulmonary and Pulmonary Tuber- 
culosis Cases: Factors Influencing the Site of Reactivation. International Journal of Tuberculosis and Lung Disease, 9, 1220-1223.

[16] Sharma, S.K. and Mohan, A. (2012) Extrapulmonary Tuberculosis. Indian Journal of Medical Research, 136, 11291166.

[17] Datiko, D.G., Yassin, M.A., Chekol, L.T., Kabeto, L.E. and Lindtjorn, B. (2008) The Rate of TB/HIV Co-Infection Depends on the Prevalence of HIV Infection in a Community. BMC Public Health, 8, 266. http://dx.doi.org/10.1186/1471-2458-8-266

[18] John, M., Menezes, N. and Grobusch, M.P. (2007) High Tuberculosis and HIV Co-infection Rate, Johannesburg. Emerging Infectious Diseases, 13, 795-796.

[19] Dharma, S.K., Aggarwal, P.S. and Saha, P.K. (2003) Increasing HIV Seropositivity among Adult Tuberculosis Patients in Delhi. Indian Journal of Medical Research, 117, 239-242.

[20] Centres for Disease Control and Prevention (2014) HIV/AIDS Statistics. www.cdc.gov/hiv/statistics/basics/

[21] World Health Organisation (WHO) HIV/AIDS Fact Sheet. www.who.int/mediacentre/factsheets/F360/en/

[22] Marlink, R.G. and Kotin, A.G. (2004) Global AIDS Crisis: A Reference Handbook. ABC-CLIO Inc., Carlifonia, 54.

[23] Federal Ministry of Health of Nigeria (2012) 2010 National HIV Sero-Prevalence Sentinel Survey. Federal Ministry of Health, Abuja.

[24] Obidoa, C.A. and Cromley, R.G. (2012) A Geographical Analysis of HIV/AIDS Infection in Nigeria, $1991-2001$. Journal of Social, Behavioural and Health Sciences, 6, 13-29. 
Scientific Research Publishing (SCIRP) is one of the largest Open Access journal publishers. It is currently publishing more than 200 open access, online, peer-reviewed journals covering a wide range of academic disciplines. SCIRP serves the worldwide academic communities and contributes to the progress and application of science with its publication.

Other selected journals from SCIRP are listed as below. Submit your manuscript to us via either submit@scirp.org or Online Submission Portal.
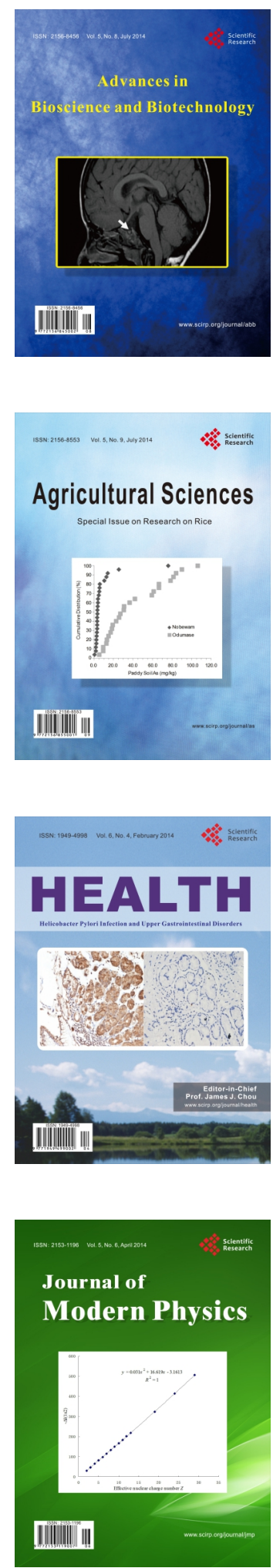
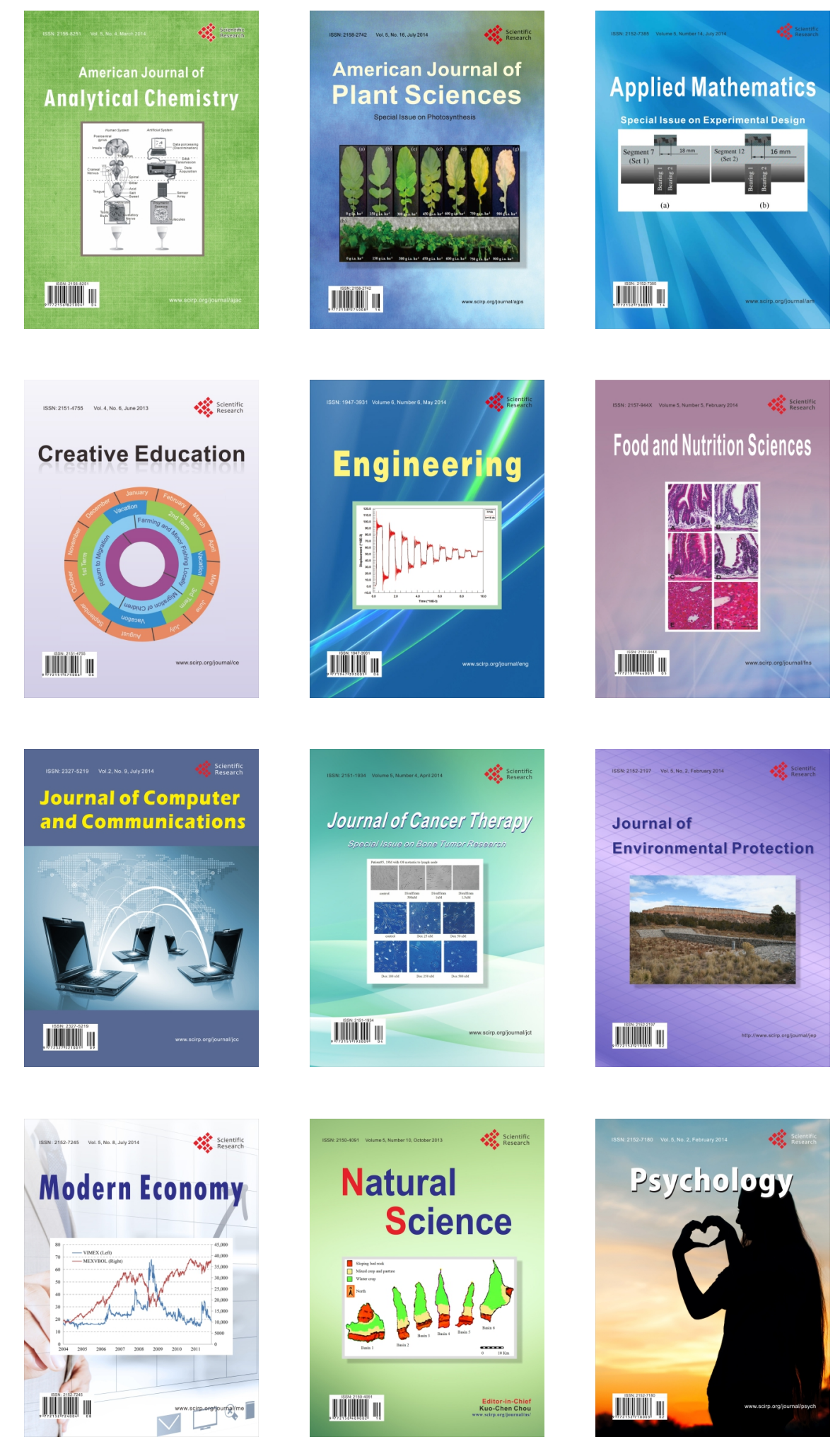